\title{
Early growth retardation induced by excessive exposure to glucocorticoids in utero selectively increases cardiac GLUT1 protein expression and Akt/protein kinase B activity in adulthood
}

\author{
M L Langdown, M J Holness and M C Sugden \\ Department of Diabetes and Metabolic Medicine, Division of General and Developmental Medicine, St Bartholomew's and the Royal London School of \\ Medicine and Dentistry, Queen Mary, University of London, London, UK \\ (Requests for offprints should be addressed to M C Sugden, Department of Diabetes and Metabolic Medicine, Medical Sciences Building, Queen Mary, \\ Mile End Road, London E1 4NS, UK; Email: m.c.sugden@qmw.ac.uk)
}

\begin{abstract}
In the rat, dexamethasone treatment during late pregnancy leads to intrauterine growth retardation and is used as a model of early programming of adult onset disease. The present study investigated whether pre-natal dexamethasone treatment modifies cardiac glucose transporter (GLUT) protein expression in adulthood and identified signalling pathways involved in the response. Dexamethasone $(100 \mu \mathrm{g} / \mathrm{kg}$ body wt per day) administered via an osmotic pump to pregnant rats (day 15 to day 21; term $=22$ to 23 days) reduced fetal weight at day 21 and caused hypertension, hyperinsulinaemia and elevated corticosterone levels in the adult (24-week-old) male offspring. Cardiac GLUT1 protein expression was selectively up-regulated ( $2 \cdot 5$-fold; $P<0 \cdot 001)$, in the absence of altered cardiac GLUT4 protein expression, in adult male offspring of dexamethasone-treated dams. Maternal dexamethasone treatment did not influence cardiac GLUT1 protein expression during fetal or early post-natal life. We examined potential regulatory signalling proteins that might mediate
\end{abstract}

up-regulation of cardiac GLUT1 protein expression in adulthood. We observed marked $(2 \cdot 2$-fold; $P<0 \cdot 01)$ activation of $\mathrm{Akt} /$ protein kinase $\mathrm{B}(\mathrm{PKB})$, together with modest activation of the anti-apoptotic protein kinase $\mathrm{C}$ $(\mathrm{PKC})$ isoforms PKC $\alpha(88 \%, P<0 \cdot 05)$ and PKC $\varepsilon(56 \%$, $P<0.05)$ in hearts of the early-growth-retarded male offspring. These effects were, however, observed in conjunction with up-regulation of cardiac protein expression of PKC $\beta_{1}(191 \%, P<0 \cdot 01)$, PKC $\beta_{2}(49 \%, P<0 \cdot 05)$ and PKC $\delta(35 \% ; P<0 \cdot 01)$, effects that may have adverse consequences. Maternal dexamethasone treatment was without effect on cardiac extracellular signal-related kinase (ERK) 1 or ERK2 activity in adulthood. In conclusion, our data demonstrate an effect of maternal dexamethasone treatment to up-regulate cardiac GLUT1 protein expression in early-growth-retarded, hypertensive, hyperinsulinaemic adult male offspring, an effect observed in conjunction with activation of Akt/PKB.

Journal of Endocrinology (2001) 169, 11-22

\section{Introduction}

Under resting conditions, the adult heart derives about $70 \%$ of its energy from the oxidation of lipids, and the remainder primarily from glycolysis and glucose oxidation (Taegtmeyer 1994). However, specific situations exist that are known to be associated with increased cardiac glucose utilisation: these include late fetal life (Santalucia et al. 1992), myocardial ischaemia (Brosius et al. 1997) and pressure-overload-induced cardiac hypertrophy (Bishop \& Altschuld 1970, Taegtmeyer \& Overturf 1988, Christe \& Rodgers 1994). Glucose transport is rate limiting for cardiac glucose metabolism. Glucose enters the heart via two facilitative glucose transporters GLUT1 and GLUT4 (Mueckler 1990). GLUT1 is a major mediator of basal cardiac glucose uptake (Kraegen et al. 1993, Laybutt et al. 1997), and normally accounts for approximately $30 \%$ of the total cardiac glucose transporters in the adult heart (Fischer et al. 1997). The contribution of GLUT1 to total cardiac glucose transporter number is even higher in late fetal life and early neonatal life, when GLUT4 protein expression is relatively low (Studelska et al. 1992, Postic et al. 1994). However, the relative contribution of the two glucose transporters changes post-natally when GLUT1 protein expression is down-regulated (Studelska et al. 1992, Postic et al. 1994), whereas that of GLUT4 is up-regulated (Studelska et al. 1992, Postic et al. 1994). The post-natal down-regulation of GLUT1 has been attributed in part to reduced protein abundance of the zinc finger transcription factor Sp1 (Santalucia et al. 1999).

Impaired growth and development during fetal life and infancy in man has been associated with an increased risk for the later development of hypertension, insulin resistance syndrome (Syndrome X) and adverse coronary events 
(reviewed by Barker 1999, 2000). Excessive prenatal exposure to glucocorticoids has been suggested as a possible underlying mechanism (Benediktsson et al. 1993). In the rat, the administration of the synthetic glucocorticoid dexamethasone during the last third of pregnancy leads to intrauterine growth retardation in conjunction with hypertension (Levitt et al. 1996, reviewed by Barker 1999) and glucose intolerance (Nyirenda et al. 1998) in later life, a pattern paralleling that found in man. It has been proposed that prenatal exposure to excessive glucocorticoids up-regulates glucocorticoid activity throughout life by decreasing the expression of hippocampal glucocorticoid receptors, thereby blunting feedback control of glucocorticoid secretion (Levitt et al. 1996). Increased myocardial glucose uptake is observed in conjunction with increased cardiac GLUT1 expression in spontaneously hypertensive rats (Paternostro et al. 1995). Long-term insulin treatment also up-regulates cardiac GLUT1 protein expression (Laybutt et al. 1997), and sustained hyperinsulinaemia is one of the major characteristics of the insulin resistance syndrome (reviewed by Reaven 1995). Thus, at least two of the pathophysiological features associated with impaired early growth (hypertension and hyperinsulinaemia) are associated with up-regulation of cardiac GLUT1 protein expression.

In some, but not all, studies, mitogen-activated protein kinases (MAPKs) have been identified as being involved in the cardiac hypertrophic response: these include p42/p44 extracellular signal-related kinases (ERK1 and ERK2) (Thorburn et al. 1994a,b, Post et al. 1996, Ramirez et al. 1997, Zechner et al. 1997, Choukroun et al. 1998, Nemoto et al. 1998, reviewed by Sugden 1999). Recent evidence has demonstrated that increased MAPK activity elicits greatly increased expression of GLUT1 in adipocytes (Yamamoto et al. 2000). Thus, MAPKs may coordinate increased cardiac GLUT1 expression with the overall cardiac hypertrophic response. Other studies have demonstrated a possible involvement of members of the protein kinase $\mathrm{C}$ (PKC) superfamily, in that chronic pressure overload activates PKC $\alpha$ and PKC $\varepsilon$ (Paul et al. 1997, Takeishi et al. 1999): once activated, PKCs are thought to directly enhance hypertrophic gene expression by acting on transcription factors such as serum response factor and Sp 1 (Sadoshima \& Izumo 1993b, Karns et al. 1995). Finally, recent studies have suggested that the multifunctional protein kinase Akt/protein kinase B (Akt/ $\mathrm{PKB}$ ) can regulate protein synthesis (and therefore cell growth) in response to insulin in cardiomyocytes from adult (Wang et al. 2000) and neonatal (Pham et al. 2000) rats in vitro. In view of the changes in cardiac GLUT1 expression observed during normal cardiac development and response to chronic hyperinsulinaemia and hypertension, we investigated whether prenatal dexamethasone treatment is associated with early or persistent changes in cardiac GLUT1 protein expression. Comparison was made with cardiac GLUT4 protein expression. In addition, given that common signals may be involved in the regulation of cardiac GLUT1 expression during cardiac development and in response to hyperinsulinaemia or hypertension, we investigated possible intracellular signalling mechanisms whereby altered cardiac GLUT1 expression might be mediated.

\section{Materials and Methods}

\section{Materials}

All organic solvents were of analytical grade and obtained from BDH Laboratories Supplies (Poole, Dorset, UK). General laboratory reagents were from Sigma Chemical Co. Ltd (Poole, Dorset, UK), with the following exceptions. ECL reagents, Hyperfilm and secondary antibodies were purchased from Amersham International plc (Amersham, Bucks, UK). Anti-GLUT1 and anti-GLUT4 polyclonal immunoglobulin $\mathrm{G}$ (IgG) antibodies and antiPKC $\beta_{1 / 2}$, anti-PKC $\delta$ and anti-PKC $\alpha$ polyclonal IgG antibodies were purchased from Insight Biotechnology Ltd (Wembley, Middlesex, UK). Anti-PKC $\varepsilon$ monoclonal IgG antibody was purchased from Transduction Labs. (Lexington, KY, USA). Anti-phospho-MAPK and antiphospho-Akt/PKB were purchased from New England Biolabs Ltd (Hitchin, Herts, UK). Dexamethasone (sodium phosphate) was obtained from David Bull Laboratories (Warwick, UK). Bradford reagents were purchased from BioRad Ltd (Hemel Hempstead, Herts, $\mathrm{UK})$. Kits for the measurement of corticosterone were purchased from ICN Pharmaceuticals, Inc. (Basingstoke, Hants, UK). Kits for determination of plasma insulin concentrations were from Phadeseph Pharmacia (Uppsala, Sweden). Alzet osmotic mini-pumps were purchased from Charles River (Margate, Kent, UK).

\section{Animals}

All studies were conducted in adherence to the regulation of the United Kingdom Animal Scientific Procedures Act (1986). Female albino Wistar rats (200-220 g) were purchased from Charles River. Rats were maintained at a temperature of $22 \pm 2{ }^{\circ} \mathrm{C}$ and subjected to a $12 \mathrm{~h}$ light/ $12 \mathrm{~h}$ darkness cycle. Rats were maintained on standard, pelleted rodent diet purchased from Special Diet Services (Witham, Essex, UK). This diet consisted of 52\% carbohydrate, $15 \%$ protein, 3\% lipid and 30\% non-digestible residue (by wt), and contained $2 \cdot 61 \mathrm{Kcal} / \mathrm{g}$ metabolisable energy. In all experiments, rats were allowed access ad libitum to standard diet and water.

\section{Tissue and blood sampling}

All studies were undertaken with rats in the absorptive state (between 1000-1100 h). Rats were anaesthetised by 
injection of sodium pentobarbital $(60 \mathrm{mg} / \mathrm{ml}$ in $0.9 \%$ $\mathrm{NaCl} ; 1 \mathrm{ml} / \mathrm{kg}$ body wt i.p.) and, once locomotor activity had ceased, hearts were rapidly excised and freezeclamped using aluminium clamps pre-cooled in liquid nitrogen. Frozen hearts were stored in liquid nitrogen. Blood was sampled from the chest cavity after the removal of the heart. Blood was sampled from fetuses after decapitation and from neonatal rats after decapitation following anaesthesia by injection of sodium pentobarbital $(60 \mathrm{mg} /$ $\mathrm{ml}$ in $0.9 \% \mathrm{NaCl} ; 1 \mathrm{ml} / \mathrm{kg}$ body wt, i.p.). Blood samples were centrifuged for $5 \mathrm{~min}$ at $12000 \mathrm{~g}$ and plasma was stored at $-20^{\circ} \mathrm{C}$.

\section{Dexamethasone administration}

Dexamethasone was administered to pregnant rats from day 15 of gestation by subcutaneous infusion via a chronically-implanted osmotic minipump, at a dose of $100 \mu \mathrm{g} / \mathrm{kg}$ body wt per day. This dosage has been used previously to elicit hypertension in the adult offspring (Levitt et al. 1996); the protocol used in the present experiments differs from that used previously in that in our studies dexamethasone was infused at a steady rate, whereas in the previous study, dexamethasone was administered daily via a single bolus injection. An initial priming dose $(0 \cdot 1 \mathrm{mg})$ of dexamethasone was also given by subcutaneous injection before minipump implantation. The minipumps were not removed at birth to avoid handling and anaesthesia of the dams. Undue stress immediately post partum can lead to abandonment of the litter, as well as to interrupted suckling over a critical developmental period. The minipumps were set to deliver a fixed volume that was exhausted after 7 days. Sham operations involving incision and manipulation under anaesthesia identical to the procedure for implantation of the osmotic minipump were undertaken on control pregnant rats.

\section{Western blotting}

Cardiac samples (approx. $100 \mathrm{mg}$ ) were homogenised using a Polytron Tissue homogeniser (PT 10 probe; position $5,15 \mathrm{~s}$ ) in $1 \mathrm{ml}$ ice-cold extraction buffer A (20 mM Tris, $137 \mathrm{mM} \mathrm{NaCl}, 2 \cdot 7 \mathrm{mM} \mathrm{KCl}, 1 \mathrm{mM} \mathrm{CaCl}_{2}$, $10 \%$ glycerol, 1\% Igepal, $45 \mathrm{mM}$ sodium orthovanadate, $0.2 \mathrm{mM}$ PMSF, $10 \mu \mathrm{g} / \mathrm{ml}$ leupeptin, $1.5 \mathrm{mg} / \mathrm{ml}$ benzamidine, $50 \mu \mathrm{g} / \mathrm{ml}$ aprotinin, $50 \mu \mathrm{g} / \mathrm{ml}$ pepstatin A (in DMSO), $\mathrm{pH}$ 8.0). Homogenates were placed on ice for $20 \mathrm{~min}$, centrifuged in an Eppendorf centrifuge (12000 r.p.m. for $20 \mathrm{~min}$ at $4{ }^{\circ} \mathrm{C}$ ) and the supernatants stored $\left(-20^{\circ} \mathrm{C}\right)$ until analysis. Protein concentrations were determined by the method of Bradford (1976) using bovine serum albumin (BSA) as standard. The assay was linear over the range of protein concentrations routinely used. Samples $(20-50 \mu \mathrm{g}$ total protein) were subjected to SDS-PAGE using either a $9 \%$ or a $12 \%$ resolving gel (depending on the molecular weight of the protein to be studied), with a $6 \%$ stacking gel. Following SDSelectrophoresis, resolved proteins were transferred electrophoretically to nitrocellulose membranes, and then blocked for $2 \mathrm{~h}$ at room temperature with Tris-buffered saline (TBS) supplemented with $0.05 \%$ Tween and 5\% $(\mathrm{w} / \mathrm{v})$ non-fat powdered milk. The nitrocellulose blots were incubated overnight at $4{ }^{\circ} \mathrm{C}$ with polyclonal antisera raised against each of the glucose transporters. PhosphoPKC $\alpha$, phospho-PKC $\varepsilon$, and phospho-Akt/PKB were used in a 1:100 dilution; anti-GLUT1 and anti-GLUT4 were used in a 1:150 dilution and PKC $\alpha$, PKC $\beta_{1 / 2}$, PKC $\delta$, PKC $\varepsilon$ and $\mathrm{PKC} \zeta$ in a 1:500 dilution. The blots were washed with TBST (TBS with $0.05 \%$ Tween 20) $(3 \times 5 \mathrm{~min})$ and incubated with horseradish peroxidaselinked secondary antibody IgG anti-rabbit (1:2000 in $1 \%$ (wt/vol.) non-fat milk in TBST) or horseradish peroxidase-linked secondary antibody $\operatorname{IgG}$ anti-mouse (1 in 2000) for $2 \mathrm{~h}$ at room temperature. Bound antibody was visualised using ECL according to the manufacturer's instructions. The blots were then exposed to Hyperfilm and the signals quantified by scanning densitometry and analysed with Molecular Analyst software (Biorad Ltd). An initial characterisation using competing antigenic peptides was performed to determine the specificity of the antibodies. Some antibodies recognised more than one protein, but in each case specific protein bands were identified by their specific reduction in immunoreactivity when competing peptide was included. The amounts of extracts loaded on to the gel were varied to establish that the relative densities of the bands corresponding to the individual proteins were linear with concentration. Immunoblots were performed under conditions in which autoradiographic detection was in the linear response range. Equivalence of protein loading was confirmed by Ponceau S staining. Each representative blot depicts a single gel exposed for a uniform duration.

\section{Blood pressure measurements}

Systolic blood pressures were determined by tail cuff plethysmography at room temperature in lightly anaesthetised (sodium pentobarbital; $35 \mathrm{mg} / \mathrm{kg}$ body wt) rats. All measurements were undertaken in the morning, and each rat had five blood pressure traces recorded in a single session. The coefficient of variation was 3.2\%. Blood pressures were quantified using a photoelectric sensor attached to the blood pressure monitor, in conjunction with software designed to determine pressures.

\section{Hormone and metabolite measurements}

Plasma insulin and corticosterone concentrations were measured by radioimmunoassay using commercial kits (Phadeseph Pharmacia and ICN Pharmaceuticals Inc. respectively). In the corticosterone radioimmunoassay, the 
antiserum used showed $<0.05 \%$ cross reactivity with cortisol and $<0 \cdot 01 \%$ cross reactivity with dexamethasone. It is appreciated that corticosterone levels in blood sampled from the chest cavity after terminal anaesthesia may not represent true basal corticosterone levels; however, every effort was made to standardise procedures and time taken for sampling between the experimental groups and thus values are directly comparable.

\section{Statistical analysis}

Results are presented as the mean \pm S.E.M., with the numbers of rats in parentheses. Statistical analysis was performed by ANOVA followed by Fisher's post-hoc tests for individual comparisons or Student's $t$-test as appropriate (Statview, Abacus Concepts, Inc., Berkeley, CA, USA).

\section{Results}

Maternal dexamethasone treatment during pregnancy in the rat leads to intrauterine growth retardation, together with hyperinsulinaemia, hypertension and elevated corticosterone levels in the adult male offspring

We validated the procedure for dexamethasone administration by measurement of fetal weight and blood pressure and plasma analytes in the adult offspring. Maternal dexamethasone administration via an indwelling osmotic pump at a dose of $100 \mu \mathrm{g} / \mathrm{kg}$ body weight per day during the last week of pregnancy did not alter gestation length (control 22.3 \pm 0.3 days; dexamethasone $22 \cdot 8 \pm 0 \cdot 3$ days), offspring number (control $12 \pm 1$; dexamethasone $12 \pm 1$ ) or offspring viability (results not shown), but led to a significant $13 \%(P<0.05)$ decrease in fetal body weight at day 21 of gestation (control $5 \cdot 4 \pm 0.1 \mathrm{~g}$; dexamethasone $4 \cdot 7 \pm 0 \cdot 1 \mathrm{~g})$. The adult (24-week-old) male offspring of dams treated with dexamethasone (DEX offspring) had developed significant ambient hyperinsulinaemia (80\% increase; $P<0 \cdot 01)$ in conjunction with modest but significant increase in systolic hypertension $(29 \%$ increase; $P<0 \cdot 01)$ and significantly higher plasma corticosterone concentrations $(16 \%$ increase; $P<0.05)$ compared with age-matched controls (CON offspring) (Table 1). Body weight at 24 weeks of age was unaffected by maternal dexamethasone treatment (control $435 \pm 10 \mathrm{~g}$; dexamethasone $457 \pm 9 \mathrm{~g})$.

Maternal dexamethasone treatment is associated with selective up-regulation of GLUT1 protein expression in hearts of early-growth-retarded adult male offspring

GLUT1 protein expression was analysed by Western blotting in hearts of adult male CON and DEX offspring
Table 1 Maternal dexamethasone (DEX) treatment leads to hyperinsulinaemia, hypertension and elevated corticosterone levels in the adult male offspring. Systolic blood pressures were determined by tail cuff plethysmography at room temperature in lightly anaesthetised rats. Plasma insulin and corticosterone concentrations were measured by radioimmunoassay using commercial kits. Further details are provided in the Materials and Methods section. Data are means \pm S.E.M. The number of observations (given in parentheses) indicates the number of individual control or early-growth-retarded adult offspring sampled. Each group was comprised of rats obtained from 3-5 separate litters

\begin{tabular}{|c|c|c|}
\hline & CON & DEX \\
\hline Plasma insulin $(\mu \mathrm{U} / \mathrm{ml})$ & $18 \pm 6(4)$ & $32 \pm 6(4)^{* *}$ \\
\hline Plasma corticosterone (ng/ml) & $296 \pm 13(10)$ & $342 \pm 10(6)^{*}$ \\
\hline Systolic blood pressure $(\mathrm{mmHg})$ & $80 \pm 2(5)$ & $103 \pm 5(5)^{* *}$ \\
\hline
\end{tabular}

at 24 weeks of age (Fig. 1, left hand panel). Direct comparison of adult CON and DEX offspring revealed that maternal dexamethasone treatment led to a marked $(2 \cdot 5$-fold $)$ and significant $(P<0 \cdot 001)$ increase in GLUT1 relative protein abundance in the hearts in earlygrowth-retarded adult (24-week-old) male offspring of dexamethasone-treated dams compared with the agematched controls. Cardiac GLUT4 protein expression in adulthood was not targeted by dexamethasone-induced early-growth retardation (Fig. 1, right hand panel).

A role for $A k t / P K B$, but not ERK 1/2, in up-regulation of cardiac GLUT1 protein expression in hearts of early-growth-retarded adult male offspring

We sought to identify the signalling pathways that might be involved in up-regulation of cardiac GLUT1 protein expression in the early-growth-retarded adult male offspring of dexamethasone-treated dams. There was no significant effect of maternal dexamethasone treatment on ERK1 activity (relative abundance: CON, 1.00 $\pm 0 \cdot 06$; DEX $0.98 \pm 0 \cdot 10$ ) or ERK2 activity (relative abundance: CON, $1 \cdot 00 \pm 0 \cdot 09$; DEX 1.04 \pm 0.02$)$, as assessed by Western analysis using phosphorylation-specific antibodies in 24-week-old male offspring. In contrast, using phosphorylation-specific antibodies, we observed a marked and significant $2 \cdot 2$-fold $(P<0 \cdot 01)$ activation of $\mathrm{Akt} / \mathrm{PKB}$ in the hearts of adult early-growth-retarded male offspring (Fig. 2).

PKC isoform expression and activity is modified in hearts of early-growth-retarded adult male offspring

In the heart, PKC isoforms $\alpha, \beta_{1 / 2}, \delta, \varepsilon$ and $\xi$ have been identified in rat neonatal cardiac myocytes (Bogoyevitch et al. 1993, Rybin \& Steinberg 1994). In adult rat myocytes and myocardium, PKC isoforms $\delta$ and $\varepsilon$ seem to 

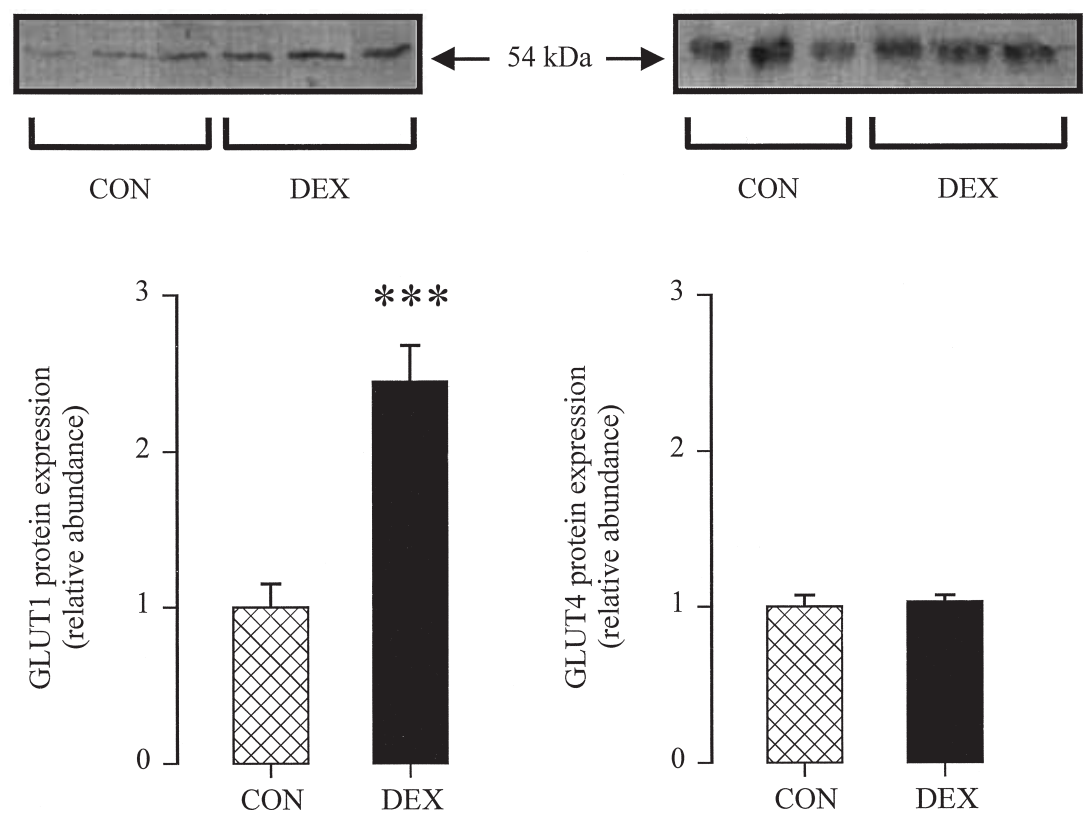

Figure 1 Maternal dexamethasone treatment selectively up-regulates GLUT1 protein expression in hearts of early-growth-retarded adult male offspring. GLUT1 protein expression (left hand panel) and GLUT4 protein expression (right hand panel) were analysed by Western blotting in homogenates of hearts obtained from 24-week-old adult male offspring of control dams (CON; hatched bars) and of dams treated with dexamethasone from day 15 of gestation (DEX; solid bars). Experimental data are presented normalised to the corresponding CON values. Representative immunoblots from gels exposed for a uniform duration are also shown. Data are means \pm S.E.M. for 8 (GLUT1) or 5 (GLUT4) hearts obtained from individual control or early-growth-retarded adult offspring. Each data group was comprised of rats from at least three separate litters. Statistically significant effects of maternal dexamethasone treatment are indicated: ${ }^{* * *} P<0 \cdot 001$.

be maintained with age, whereas other PKC isoforms may decline (Rybin \& Steinberg 1994, Clerk et al. 1995). We performed an extensive Western blot survey of PKC expression using protein extracts from hearts of control and early-growth-retarded 24-week-old rats, and identified immunoreactivity for PKC isoforms $\alpha, \beta_{1 / 2}, \delta, \varepsilon$, and $\xi$ (Fig. 3). Western blot quantification demonstrated significant increases in the classical PKC isoforms PKC $\beta_{1}$ $(191 \%, P<0 \cdot 01)$ and PKC $\beta_{2}(49 \%, P<0 \cdot 05)$ in hearts of adult early-growth-retarded male offspring. The protein expression of the novel PKC isoform PKC $\delta$ was also modestly increased (by $35 \% ; P<0 \cdot 01$ ); however, that of PKC $\varepsilon$ and the atypical PKC isoform PKC $\xi$ was unchanged (Fig. 3).

PKC $\alpha$ and PKC $\varepsilon$ are activated by phosphorylation. The activation state of these PKC isoforms was investigated using phosphorylation specific antibodies (Fig. 4). A significant activation of PKC $\alpha(88 \%, P<0.05)$ was observed in the hearts of the early-growth-retarded male offspring. We also observed a more subtle, but nonetheless reproducible and significant, 56\% $(P<0.001)$ increase in $\mathrm{PKC} \varepsilon$ phosphorylation state in the hearts of the early-growth-retarded rats.
Maternal dexamethasone treatment during pregnancy does not affect the ontogeny of cardiac GLUT1 expression during periand early post-natal life

Relative protein expression of GLUT1 in hearts of control rats and rats in the experimental group (maternal dexamethasone treatment from day 15 of gestation) during late fetal life (day 21) and during the first 3 weeks of post-natal life, as quantified by Western blot analysis, are shown in Fig. 5 (left hand panel). Cardiac GLUT1 protein expression in late fetal life was not signficantly affected by maternal dexamethasone treatment. Confirming previous studies (Studelska et al. 1992, Postic et al. 1994), we observed a marked decline in cardiac GLUT1 protein expression during early post-natal development. Investigating the time course of cardiac GLUT1 protein expression down-regulation in detail, we found that cardiac GLUT1 protein expression in the control group was suppressed to a level of $69 \%(P<0 \cdot 05)$ of that of the fetal (day 21) level at post-natal day 7 , and continued to decline significantly between post-natal days 7 and 15 (to $46 \%$ of the fetal day 21 value; $P<0 \cdot 001$ ). However, by post-natal day 21, cardiac GLUT1 relative abundance in 21-day-old 

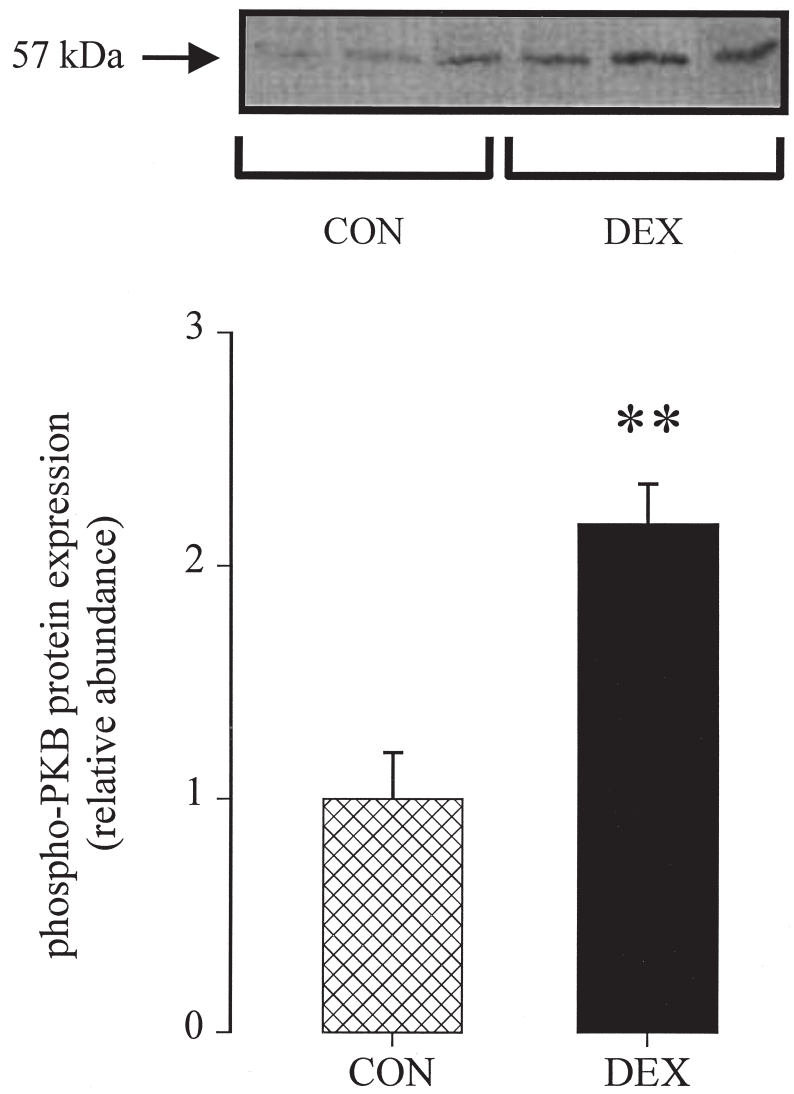

Figure $2 \mathrm{Akt} / \mathrm{PKB}$ activity is increased in hearts of early-growthretarded adult male offspring. Akt/PKB activation was assessed by Western analysis using phosphorylation-specific antibodies in 24-week-old male offspring. Experimental data are presented normalised to the corresponding CON values. Representative immunoblots from gels exposed for a uniform duration are also shown. Data are means \pm S.E.M. for 6 hearts obtained from individual control (CON) or early-growth-retarded (DEX) adult offspring. Each data group was comprised of rats from at least three separate litters. Statistically significant effects of maternal dexamethasone treatment are indicated: ${ }^{* *} P<0 \cdot 01$.

animals was only $39 \%$ of that observed in late fetal life $(P<0 \cdot 001)$, and continued to decline in adulthood (results not shown). As with CON offspring, GLUT1 protein expression was down-regulated during early post-natal development in hearts of DEX offspring at post-natal days 7, 15 and 21 (to 58\%, 52\% and 52\% respectively; $P<0 \cdot 001$ at each point). However, no significant differences in cardiac GLUT1 protein expression were observed between CON and DEX offspring at post-natal days 7 and 15, although GLUT1 expression at post-natal day 21 was modestly higher $(33 \%, P<0 \cdot 05)$ in hearts of DEX offspring compared with CON offspring.

Post-natal up-regulation of cardiac GLUT4 protein expression is retarded by maternal dexamethasone treatment

The relative levels of GLUT4 protein expression in hearts of control rats at intervals during peri- and early post-natal

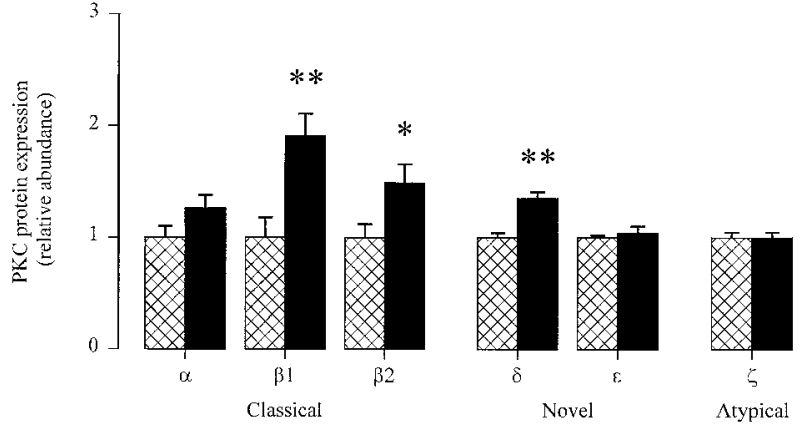

Figure 3 PKC isoform protein expression in hearts of earlygrowth-retarded adult male offspring. Western blot analysis was undertaken using antibodies specific for PKC isoforms $\alpha, \beta 1 / 2, \delta$, $\varepsilon$, and $\xi$ using protein extracts from hearts of control rats (crosshatched bars) and early-growth-retarded 24-week-old rats (solid bars). Experimental data are presented normalised to the corresponding CON values. Data are means \pm S.E.M. for 6 (PKC isoforms $\alpha, \beta 1 / 2, \delta$ and $\varepsilon$ ) or 3 (PKC isoform $\xi$ ) hearts obtained from individual control or early-growth-retarded adult offspring. Each data group was comprised of rats from at least three separate litters. Statistically significant effects of maternal dexamethasone treatment are indicated: ${ }^{*} P<0 \cdot 05 ;{ }^{*} P<0 \cdot 01$.

development, as quantified by Western blot analysis, are shown in Fig. 5 (right hand panel). In the control group, cardiac GLUT4 protein expression was modestly increased at post-natal day 7 (by 45\%; not significant (NS)), but subsequently increased dramatically (to $296 \%$ of the fetal day 21 value; $P<0.001$ ) between post-natal days 7 and 15 . There was a further modest rise in GLUT4 protein expression between post-natal days 15 and 21. Thus, cardiac protein expression of GLUT4 increased by approximately $3 \cdot 4$-fold $(P<0 \cdot 01)$ between fetal day 21 and post-natal day 21. Cardiac GLUT4 expression was subsequently maintained, with little further increase with age (results not shown). Contrasting with the pattern observed in the control group, GLUT4 expression in hearts of DEX offspring tended to be suppressed (by approx. 40\% (NS) compared with the late-fetal level) at post-natal day 7 . Furthermore, while the cardiac protein expression of GLUT4 increased between post-natal days 7 and 15 (to $200 \%$ of the fetal day 21 value; $P<0 \cdot 05)$ in the DEX offspring, cardiac GLUT4 expression at post-natal day 15 was only approximately $68 \%$ of that found in control rats at this stage of development $(P<0 \cdot 05)$. Thus there appears no necessity for stringent reciprocality of protein expression of GLUT1 and GLUT4 in the early post-natal period for the developing rat heart. Protein expression of GLUT4 in DEX offspring further increased between post-natal days 15 and 21, such that GLUT4 protein expression did not differ significantly between CON and DEX offspring at post-natal day 21. As relative abundance of GLUT4 protein in hearts of offspring of dexamethasone-treated dams did not differ from controls at post-natal day 21, post-natal recovery of cardiac GLUT4 protein expression 

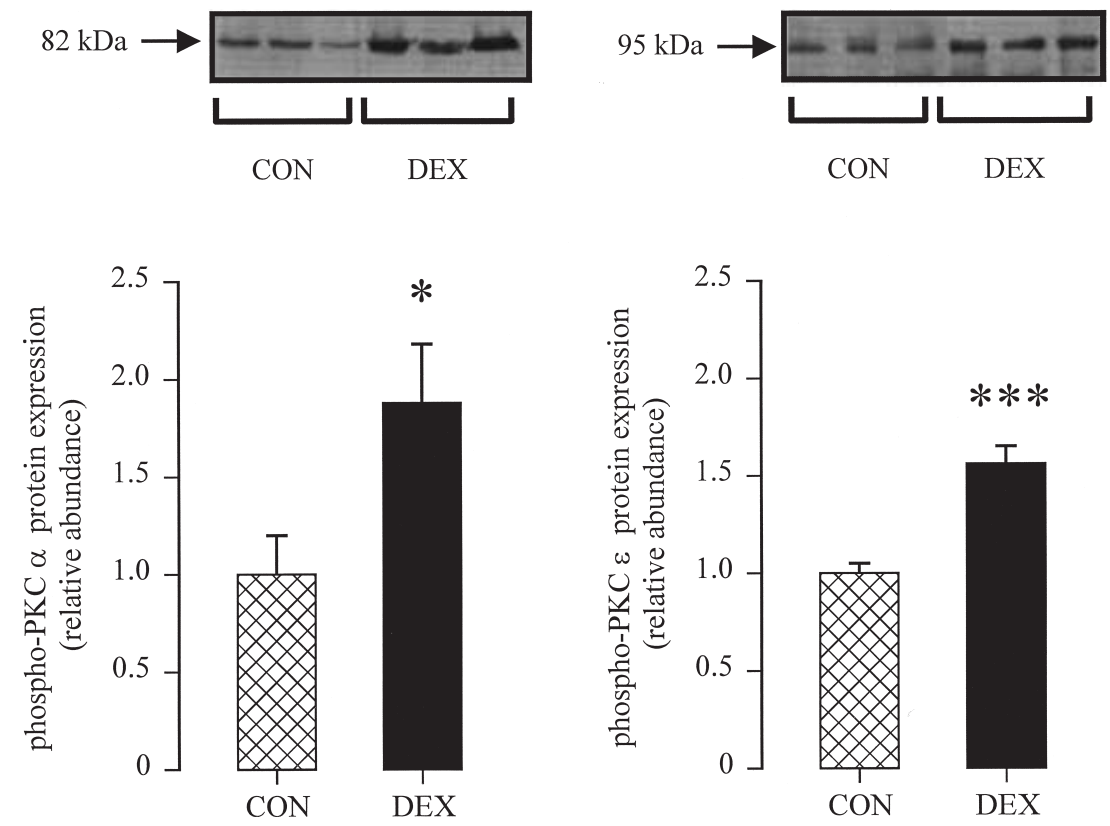

Figure 4 Activation state of PKC $\alpha$ and PKC $\varepsilon$ in hearts of early-growth-retarded adult male offspring. The activation state of PKC $\alpha$ and PKC $\varepsilon$ was assessed by Western analysis using phosphorylation-specific antibodies in 24-week-old male offspring. Experimental data are presented normalised to the corresponding CON values. Representative immunoblots from gels exposed for a uniform duration are also shown. Data are means \pm S.E.M. for 8 hearts obtained from individual control (CON) or early-growth-retarded (DEX) adult offspring. Each data group was comprised of rats from at least three separate litters. Statistically significant effects of maternal dexamethasone treatment are indicated: ${ }^{*} P<0 \cdot 05 ;{ }^{* *} P<0 \cdot 001$.

was evident. As in CON offspring, little further change in cardiac GLUT4 protein expression occurred during subsequent development in DEX offspring (results not shown).

\section{Discussion}

In the present study, we examined the effect of earlygrowth retardation induced by maternal dexamethasone treatment during the last third of pregnancy in the rat on cardiac GLUT protein expression in the adult male offspring, and showed that cardiac GLUT1 protein expression is selectively up-regulated. Absence of effects of maternal dexamethasone treatment on cardiac GLUT1 protein expression during early post-natal life suggest that selective up-regulation of cardiac GLUT1 expression in early-growth-retarded male offspring is secondary to effects of early glucocorticoid exposure, possibly through effects to programme the development of hyperinsulinaemia and/or hypertension. Analysis of possible signalling pathways suggests that activation of Akt/PKB (possibly secondary to hyperinsulinaemia) and PKC (possibly secondary to hypertrophic stimulation through hypertension) may mediate the effect.
In the present experiments, cardiac GLUT1 protein expression was up-regulated in hearts of early-growthrestricted male rats, long after exposure to the stimulus (maternal dexamethasone treatment) eliciting growth retardation, suggesting that the early intervention has persistent consequences. Although the modest developmental decline in cardiac GLUT1 expression between post-natal days 15 and 21 was slightly attenuated in offspring of dexamethasone-treated dams, GLUT1 protein expression in hearts of offspring of dexamethasone-treated dams was comparable to that of control offspring during the first 2 weeks of life. This finding suggests that dexamethasone per se is unimportant in mediating this effect, and thus increased cardiac GLUT1 expression is an indirect effect of 'programming' of other parameters. Hypertension, as is observed in early-growth-retarded rats in the present study, is an established stimulus for cardiac hypertrophy, and previous studies have reported increased GLUT1 mRNA and GLUT1 protein expression in a canine model of persistent myocardial ischaemia (Brosius et al. 1997). Conversely, cardiac GLUT1 protein expression falls during fasting, when insulin levels are low, and maintaining insulin levels (by insulin infusion at euglycaemia) during fasting prevents the decline in GLUT1 (Laybutt et al. 1997): insulin levels are elevated in 

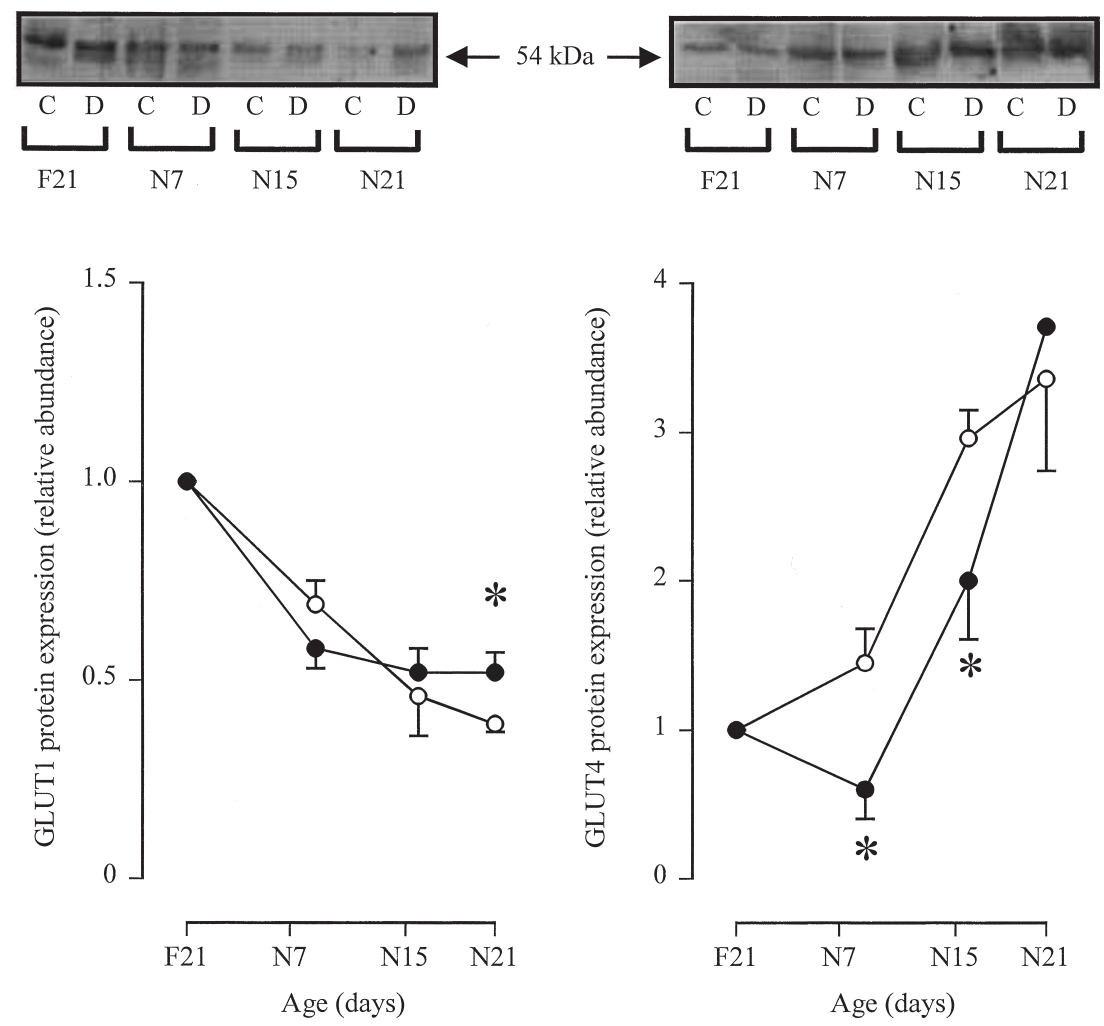

Figure 5 Ontogeny of cardiac GLUT1 and GLUT4 protein expression during peri- and early post-natal life. GLUT1 and GLUT4 protein expression was determined by Western blot analysis of homogenates of hearts obtained from rats at approximately weekly intervals during the first three weeks of post-natal development (7 days, N7; 15 days, N15; and 21 days, N21). Relative protein expression of GLUT1 in hearts of control (CON) rats (open symbols) and rats in the experimental group (maternal dexamethasone treatment from day 15 of gestation) (closed symbols) are shown in the left hand panel. The relative levels of GLUT4 protein expression in hearts of control (open symbols) and experimental rats (closed symbols) at intervals during peri- and early post-natal development, as quantified by Western blot analysis, are shown in the right hand panel. Data are presented relative to the CON values in 21-day-old fetuses (F21) together with representative immunoblots (control, C; dexamethasone-treated, D). Data are means \pm S.E.M. for pooled hearts obtained from individual litters of control dams (3) or dexamethasone-treated dams (6). GLUT1 protein expression was down-regulated during early post-natal development in hearts of CON offspring at post-natal days $7(P<0.05), 15(P<0.001)$ and $21(P<0.001)$ and in DEX offspring at post-natal days 7, 15 and 21 ( $P<0 \cdot 001$ at each point). GLUT4 protein expression was up-regulated during early post-natal development in hearts of CON offspring at post-natal days $15(P<0 \cdot 05)$ and $21(P<0.05)$ and in DEX offspring at post-natal days 15 and 21 ( $P<0.05$ at each point). Statistically significant effects of maternal dexamethasone treatment are indicated: ${ }^{*} P<0 \cdot 05$.

early-growth-retarded rats in the present study. Thus, either hypertension or hyperinsulinaemia might underlie increased cardiac GLUT1 expression.

Insight into which of these possible signals might be instrumental in this effect was gained from analysis of reactive signalling pathways. Insulin binds to a cell surface receptor and activates an intrinsic receptor tyrosine kinase, a process that ultimately stimulates two major signalling cascades (Shepherd et al. 1998). One cascade leads to the activation of MAPK and the phosphorylation of transcrip- tion factors (Robinson \& Cobb 1997). The second cascade involves phosphatidylinositol-3 kinase (Toker \& Cantley 1997) and numerous potential downstream effectors, including the serine/threonine kinase Akt/PKB (Coffer et al. 1998). In the present study, we observed that increased GLUT1 protein expression in hearts of earlygrowth-retarded adult male rats was associated with significant activation of $\mathrm{Akt} / \mathrm{PKB}$ in the heart, as assessed from increased relative abundance of phospho-Akt/PKB. $\mathrm{Akt} / \mathrm{PKB}$ activity reflects contributions from three distinct 
isozymes (Akt1-3), all of which are regulated primarily by phosphorylation (Coffer et al. 1998). Akt1/PKB $\alpha$ is the predominant isoform in most tissues, whereas Akt3/ $\mathrm{PKB} \gamma$ shows a restricted pattern of expression. The highest expression of $\mathrm{Akt} 2 / \mathrm{PKB} \beta$ is observed in insulinresponsive tissues, including the heart. Although data as to whether Akt/PKB can mediate transcriptional responses to insulin are conflicting (see e.g. O'Brien \& Granner 1996, Agati et al. 1998, Cichy et al. 1998, Dickens et al. 1998, Liao et al. 1998, Wang \& Sul 1998), Barthel et al. (1999) found that Akt/PKB can induce GLUT1 gene transcription in mouse hepatoma cells, activation of the Akt1 kinase suffices to induce GLUT1 transcription and GLUT1 protein acumulation to an extent similar to that induced by insulin, and expression of an inactive Akt1 partially inhibits the ability of insulin to stimulate GLUT1 gene expression. It is therefore concluded that an increase in Akt/PKB activity may be an important event in the signalling pathway through which insulin may regulate GLUT1 expression in the adult heart. As well as influencing glucose metabolism, evidence is mounting that one of the major functions of Akt/PKB is to promote cell survival and to block apoptosis. Although downstream cellular processes regulated by $\mathrm{Akt} / \mathrm{PKB}$ in the present study were not examined, our data also imply that increased $\mathrm{Akt} / \mathrm{PKB}$ may confer resistance to apoptosis in hearts of early-growth-retarded offspring.

Studies, mainly with neonatal rat myocytes, demonstrate associations between hypertrophic stimulation and all three main branches of the MAPK signalling cascade, namely ERKs, Jun-N-terminal kinases (JNKs) and p38s (Sadoshima \& Izumo 1993a, Bogoyevitch et al. 1994, Thorburn et al. 1994a,b, Post et al. 1996, Ramirez et al. 1997, Zechner et al. 1997, Choukroun et al. 1998, 1999, Nemoto et al. 1998, Wang et al. 1998a,b. Hines et al. 1999, reviewed by Sugden 1999). The ERKs also induce GLUT1 expression at the level of transcription (Montessuit \& Thorburn 1999) and are thought to be anti-apoptotic, whereas activation of JNK and p38 MAPKs is generally associated with promotion of apoptosis. In the present study of adult rat hearts, we found no evidence for activation of ERK 1 and 2, and in the light of this negative finding together with that of activation of $\mathrm{Akt} / \mathrm{PKB}$, we did not go on to investigate whether the other two main branches of the MAPK signalling cascade (JNKs and p38s), were similarly unaffected.

The protein expression of most PKC isoforms is downregulated in the heart after birth (Bogoyevitch et al. 1993, Rybin \& Steinberg 1994, Clerk et al. 1995). Hypertrophic stimulation of the adult heart is accompanied by recapitulation of the expression of certain fetal genes. In the present experiments, Western blot quantification demonstrated selective increases in protein expression of both classical and novel PKC isoforms in hearts of early-growth-retarded adult rats. In that the fetal PKC isoform expression programme is not globally reiterated, these data indicate that the cardiac fetal genes for individual $\mathrm{PKC}$ isoforms are regulated independently. Within this context, it is of interest that in our experiments the fetal programme is recapitulated with respect to up-regulation of cardiac GLUT1 protein expression, but not with respect to GLUT4 protein expression (i.e. GLUT4 protein expression remains high despite up-regulation of GLUT1). Thus, available data suggest that the mechanisms or regulation of cardiac GLUT1 expression observed in adulthood in our model of early-growth retardation are distinct from those responsible for modulating cardiac GLUT4 protein expression. In support of independent regulation of GLUT1 and GLUT4 protein expression in the adult heart, pressure-overload cardiac hypertrophy induced by aortic banding is associated with downregulation of GLUT4 protein expression in the absence of any change in GLUT1 expression (Depre et al. 1998).

We identified modest but significant activation of PKC $\alpha$ and $\varepsilon$ by phosphorylation, together with significant up-regulation of cardiac PKC $\beta_{1 / 2}$ and PKC $\delta$ protein expression in hearts of the early-growth-retarded male rats. PKC $\alpha$ and $\varepsilon$ have been reported previously to be up-regulated in pressure-overload hypertrophy in the rat (Paul et al. 1997, Takeishi et al. 1999). The induction of apoptosis by ceramide involves the dephosphorylation and inhibition of PKC $\alpha$ (Lee et al. 1996), whereas a reduction in the level of PKC $\alpha$ expression results in apoptosis in a number of cell types (Haimovitz-Friedman et al. 1994, Dooley et al. 1998, Whelan \& Parker 1998). Thus, the increase in PKC $\alpha$ activity observed in the hearts of early-growth-restricted male rats in the present experiments both mimics that observed in pressure-overload hypertrophy and would be predicted to suppress cardiac myocyte apoptosis. PKC $\varepsilon$ signalling is important for normal post-natal maturation of myocardial development (Bogoyevitch et al. 1993, Rybin \& Steinberg 1994) and the suggestion has been made that activation of PKC $\varepsilon$ could be of potential therapeutic value for improving cardiac growth and survival after ischaemic insult (Mochly-Rosen et al. 2000, for review see Naruse \& King 2000). Thus, activation of PKC $\varepsilon$ in hearts of earlygrowth-retarded rats would be predicted to confer protection against ischaemia. By contrast, most studies seem to suggest that up-regulation of PKC $\beta_{1 / 2}$ may have adverse consequences, including decrease in cardiac contractility (Bowman et al. 1997, Takeishi et al. 1998) and PKC $\delta$ is activated in vivo by diabetes and ischaemia (Kawamura et al. 1998, Koya \& King 1998): we demonstrate up-regulation of the protein expression of all of these PKC isoforms in the hearts of early-growth-retarded offspring. Thus, overall, our results suggest that early-growth retardation induced by maternal dexamethasone treatment may evoke mechanisms to protect cardiac function that may, at least in part, attempt to counter adverse effects - perhaps secondary to programming of hypertension and/or 
abnormal glucose metabolism - that may ultimately lead to heart failure.

In conclusion, our data demonstrate up-regulation of cardiac GLUT1 protein expression in early-growthretarded, hypertensive, hyperinsulinaemic adult offspring of dexamethasone-treated dams, and suggest that GLUT1 induction may result from altered signal transduction pathways including those involving $\mathrm{Akt} / \mathrm{PKB}$ in association with activation of one or more anti-apoptotic PKC isoforms. Although activation of the MAPK pathways may be involved in signalling hypertrophic stimulation in neonatal myocytes, we found no evidence that sustained activation of ERK1 and ERK2 is obligatory for up-regulation of cardiac GLUT1 expression in adulthood.

\section{Acknowledgements}

We are grateful to the British Heart Foundation for financial support. M L L is a recipient of a British Heart Foundation studentship (FS/97079).

\section{References}

Agati JM, Yeagley D \& Quinn PG 1998 Assessment of the roles of mitogen-activated protein kinase, phosphatidylinositol 3-kinase, protein kinase $\mathrm{B}$, and protein kinase $\mathrm{C}$ in insulin inhibition of cAMP-induced phosphoenolpyruvate carboxykinase gene transcription. Journal of Biological Chemistry 273 18751-18759.

Barker DJ 1999 Fetal origins of cardiovascular disease. Annals of Medicine 31 Suppl $13-6$.

Barker DJ 2000 In utero programming of cardiovascular disease. Theriogenology 53 555-574.

Barthel A, Okino ST, Liao J, Nakatani K, Li J, Whitlock JP Jr \& Roth RA 1999 Regulation of GLUT1 gene transcription by the serine/threonine kinase Akt1. Journal of Biological Chemistry 274 20281-20286.

Benediktsson R, Lindsay RS, Noble J, Seckl JR \& Edwards CR 1993 Glucocorticoid exposure in utero: new model for adult hypertension. Lancet 341 339-341.

Bishop SP \& Altschuld RA 1970 Increased glycolytic metabolism in cardiac hypertrophy and congestive failure. American Journal of Physiology 218 153-159.

Bogoyevitch MA, Parker PJ \& Sugden PH 1993 Characterization of protein kinase $\mathrm{C}$ isotype expression in adult rat heart. Protein kinase C-epsilon is a major isotype present, and it is activated by phorbol esters, epinephrine, and endothelin. Circulation Research 72 757-767.

Bogoyevitch MA, Glennon PE, Andersson MB, Clerk A, Lazou A, Marshall CJ, Parker PJ \& Sugden PH 1994 Endothelin-1 and fibroblast growth factors stimulate the mitogen-activated protein kinase signaling cascade in cardiac myocytes. The potential role of the cascade in the integration of two signaling pathways leading to myocyte hypertrophy. Journal of Biological Chemistry 269 1110-1119.

Bowman JC, Steinberg SF, Jiang T, Geenen DL, Fishman GI \& Buttrick PM 1997 Expression of protein kinase C beta in the heart causes hypertrophy in adult mice and sudden death in neonates. Journal of Clinical Investigation 100 2189-2195.

Bradford MM 1976 A rapid and sensitive method for the quantitation of microgram quantities of protein utilizing the principle of proteindye binding. Analytical Biochemistry 72 248-254.

Brosius FC 3rd, Liu Y, Nguyen N, Sun D, Bartlett J \& Schwaiger M 1997 Persistent myocardial ischemia increases GLUT1 glucose transporter expression in both ischemic and non-ischemic heart regions. Journal of Molecular and Cellular Cardiology 29 1675-1685.

Choukroun G, Hajjar R, Kyriakis JM, Bonventre JV, Rosenzweig A \& Force T 1998 Role of the stress-activated protein kinases in endothelin-induced cardiomyocyte hypertrophy. Journal of Clinical Investigation 102 1311-1320.

Choukroun G, Hajjar R, Fry S, del Monte F, Haq S, Guerrero JL, Picard M, Rosenzweig A \& Force T 1999 Regulation of cardiac hypertrophy in vivo by the stress-activated protein kinases/c-Jun $\mathrm{NH}(2)$-terminal kinases. Journal of Clinical Investigation 104 391-398.

Christe ME \& Rodgers RL 1994 Altered glucose and fatty acid oxidation in hearts of the spontaneously hypertensive rat. Journal of Molecular and Cellular Cardiology 26 1371-1375.

Cichy SB, Uddin S, Danilkovich A, Guo S, Klippel A \& Unterman TG 1998 Protein kinase B/Akt mediates effects of insulin on hepatic insulin-like growth factor-binding protein-1 gene expression through a conserved insulin response sequence. Journal of Biological Chemistry 273 6482-6487.

Clerk A, Bogoyevitch MA, Fuller SJ, Lazou A, Parker PJ \& Sugden PH 1995 Expression of protein kinase C isoforms during cardiac ventricular development. American Journal of Physiology 269 H1087-H1097.

Coffer PJ, Jin J \& Woodgett JR 1998 Protein kinase B (c-Akt): a multifunctional mediator of phosphatidylinositol 3-kinase activation. Biochemical Journal 335 1-13.

Depre C, Shipley GL, Chen W, Han Q, Doenst T, Moore ML, Stepkowski S, Davies PJ \& Taegtmeyer H 1998 Unloaded heart in vivo replicates fetal gene expression of cardiac hypertrophy. Nature Medicine 4 1269-1275.

Dickens M, Svitek CA, Culbert AA, O'Brien RM \& Tavare JM 1998 Central role for phosphatidylinositide 3-kinase in the repression of glucose-6-phosphatase gene transcription by insulin. Journal of Biological Chemistry 273 20144-20149.

Dooley NP, Baltuch GH, Groome N, Villemure JG \& Yong VW 1998 Apoptosis is induced in glioma cells by antisense oligonucleotides to protein kinase $\mathrm{C}$ alpha and is enhanced by cycloheximide. Neuroreport 9 1727-1733.

Fischer Y, Thomas J, Sevilla L, Munez P, Becker C, Holman G, Kozba IJ, Palacin H, Testor X, Kammermeier H \& Zorzano A 1997 Insulin-induced recruitment of glucose transporter 4 (GLUT4) and GLUT1 in isolated rat cardiac myocytes. Evidence of the existence of different intracellular GLUT4 vesicle populations. Journal of Biological Chemistry 272 7085-7092.

Haimovitz-Friedman A, Balaban N, McLoughlin M, Ehleiter D, Michaeli J, Vlodavsky I \& Fuks Z 1994 Protein kinase C mediates basic fibroblast growth factor protection of endothelial cells against radiation-induced apoptosis. Cancer Research 54 2591-2597.

Hines WA, Thorburn J \& Thorburn A 1999 Cell density and contraction regulate p38 MAP kinase-dependent responses in neonatal rat cardiac myocytes. American Journal of Physiology 277 H331-H341

Karns LR, Kariya K \& Simpson PC 1995 M-CAT, CArG, and Sp1 elements are required for alpha 1 -adrenergic induction of the skeletal alpha-actin promoter during cardiac myocyte hypertrophy. Transcriptional enhancer factor-1 and protein kinase $\mathrm{C}$ as conserved transducers of the fetal program in cardiac growth. Journal of Biological Chemistry 270 410-417.

Kawamura S, Yoshida K, Miura T, Mizukami Y \& Matsuzaki M 1998 Ischemic preconditioning translocates PKC delta and -epsilon, which mediate functional protection in isolated rat heart. American Journal of Physiology 275 H2266-H2271.

Koya D \& King GL 1998 Protein kinase C activation and the development of diabetic complications. Diabetes 47 859-866.

Kraegen EW, Sowden JA, Halstead MB, Clark PW, Rodnick KJ, Chisholm DJ \& James DE 1993 Glucose transporters and in vivo 
glucose uptake in skeletal and cardiac muscle: fasting, insulin stimulation and immunoisolation studies of GLUT1 and GLUT4. Biochemical Journal 295 287-293.

Laybutt DR, Thompson AL, Cooney GJ \& Kraegen EW 1997 Selective chronic regulation of GLUT1 and GLUT4 content by insulin, glucose, and lipid in rat cardiac muscle in vivo. American Journal of Physiology 273 H1309-H1316.

Lee JY, Hannun YA \& Obeid LM 1996 Ceramide inactivates cellular protein kinase C alpha. Journal of Biological Chemistry 271 13169-13174.

Levitt NS, Lindsay RS, Holmes MC \& Seckl JR 1996 Dexamethasone in the last week of pregnancy attenuates hippocampal glucocorticoid receptor gene expression and elevates blood pressure in the adult offspring in the rat. Neuroendocrinology 64 412-418.

Liao J, Barthel A, Nakatani K \& Roth RA 1998 Activation of protein kinase $\mathrm{B} / \mathrm{Akt}$ is sufficient to repress the glucocorticoid and cAMP induction of phosphoenolpyruvate carboxykinase gene. Journal of Biological Chemistry 273 27320-27324.

Mochly-Rosen D, Wu G, Hahn H, Osinska H, Liron T, Lorenz JN, Yatani A, Robbins J \& Dorn GW 2nd 2000 Cardiotrophic effects of protein kinase $\mathrm{C}$ epsilon: analysis by in vivo modulation of $\mathrm{PKC}$ epsilon translocation. Circulation Research 86 1173-1179.

Montessuit C \& Thorburn A 1999 Transcriptional activation of the glucose transporter GLUT1 in ventricular cardiac myocytes by hypertrophic agonists. Journal of Biological Chemistry 274 9006-9012.

Mueckler M 1990 Family of glucose-transporter genes. Implications for glucose homeostasis and diabetes. Diabetes 39 6-11.

Naruse K \& King GL 2000 Protein kinase C and myocardial biology and function. Circulation Research 86 1104-1106.

Nemoto S, Sheng Z \& Lin A 1998 Opposing effects of Jun kinase and p38 mitogen-activated protein kinases on cardiomyocyte hypertrophy. Molecular and Cellular Biology 18 3518-3526.

Nyirenda MJ, Lindsay RS, Kenyon CJ, Burchell A \& Seckl JR 1998 Glucocorticoid exposure in late gestation permanently programs rat hepatic phosphoenolpyruvate carboxykinase and glucocorticoid receptor expression and causes glucose intolerance in adult offspring. Journal of Clinical Investigation 101 2174-2181.

O'Brien RM \& Granner DK 1996 Regulation of gene expression by insulin. Physiological Reviews 76 1109-1161.

Paternostro G, Clarke K, Heath J, Seymour AM \& Radda GK 1995 Decreased GLUT-4 mRNA content and insulin-sensitive deoxyglucose uptake show insulin resistance in the hypertensive rat heart. Cardiovascular Research 30 205-211.

Paul K, Ball NA, Dorn GW 2nd \& Walsh RA 1997 Left ventricular stretch stimulates angiotensin II-mediated phosphatidylinositol hydrolysis and protein kinase $\mathrm{C}$ epsilon isoform translocation in adult guinea pig hearts. Circulation Research 81 643-650.

Pham FH, Sugden PH \& Clerk A 2000 Regulation of protein kinase $\mathrm{B}$ and 4E-BP1 by oxidative stress in cardiac myocytes. Circulation Research 86 1252-1258.

Post GR, Goldstein D, Thuerauf DJ, Glembotski CC \& Brown JH 1996 Dissociation of p44 and p42 mitogen-activated protein kinase activation from receptor-induced hypertrophy in neonatal rat ventricular myocytes. Journal of Biological Chemistry 271 8452-8457.

Postic C, Leturque A, Printz RL, Maulard P, Loizeau M, Granner DK \& Girard J 1994 Development and regulation of glucose transporter and hexokinase expression in rat. American Journal of Physiolgy 266 E548-E559.

Ramirez MT, Sah VP, Zhao XL, Hunter JJ, Chien KR \& Brown JH 1997 The MEKK-JNK pathway is stimulated by alpha1-adrenergic receptor and ras activation and is associated with in vitro and in vivo cardiac hypertrophy. Journal of Biological Chemistry $\mathbf{2 7 2}$ 14057-14061.

Reaven GM 1995 The fourth musketeer - from Alexandre Dumas to Claude Bernard. Diabetologia 38 3-13.

Robinson MJ \& Cobb MH 1997 Mitogen-activated protein kinase pathways. Current Opinion in Cellular Biology 9 180-186.
Rybin VO \& Steinberg SF 1994 Protein kinase C isoform expression and regulation in the developing rat heart. Circulation Research $\mathbf{7 4}$ 299-309.

Sadoshima J \& Izumo S 1993a Signal transduction pathways of angiotensin II-induced c-fos gene expression in cardiac myocytes in vitro. Roles of phospholipid-derived second messengers. Circulation Research 73 424-438.

Sadoshima J \& Izumo S 1993 b Mechanical stretch rapidly activates multiple signal transduction pathways in cardiac myocytes: potential involvement of an autocrine/paracrine mechanism. EMBO Journal 12 1681-1692.

Santalucia T, Camps M, Castello A, Munoz P, Nuel A, Testar X, Palacin M \& Zorzano A 1992 Developmental regulation of GLUT-1 (erythroid/Hep G2) and GLUT-4 (muscle/fat) glucose transporter expression in rat heart, skeletal muscle, and brown adipose tissue. Endocrinology 130 837-846.

Santalucia T, Boheler KR, Brand NJ, Sahye U, Fandos C, Vinals F, Ferre J, Testar X, Palacin M \& Zorzano A 1999 Factors involved in GLUT-1 glucose transporter gene transcription in cardiac muscle. Journal of Biological Chemistry 274 17626-17634.

Shepherd PR, Withers DJ \& Siddle K 1998 Phosphoinositide 3-kinase: the key switch mechanism in insulin signalling. Biochemical Journal 333 471-490.

Studelska DR, Campbell C, Pang S, Rodnick KJ \& James DE 1992 Developmental expression of insulin-regulatable glucose transporter GLUT-4. American Journal of Physiology 263 E102-E106.

Sugden PH 1999 Signaling in myocardial hypertrophy: life after calcineurin? Circulation Research 84 633-646.

Taegtmeyer H 1994 Energy metabolism of the heart: from basic concepts to clinical applications. Current Problems in Cardiology 19 59-113.

Taegtmeyer H \& Overturf ML 1988 Effects of moderate hypertension on cardiac function and metabolism in the rabbit. Hypertension 11 416-426.

Takeishi Y, Chu G, Kirkpatrick DM, Li Z, Wakasaki H, Kranias EG, King GL \& Walsh RA 1998 In vivo phosphorylation of cardiac troponin I by protein kinase $\mathrm{C}$ beta2 decreases cardiomyocyte calcium responsiveness and contractility in transgenic mouse hearts. Journal of Clinical Investigation 102 72-78.

Takeishi Y, Bhagwat A, Ball NA, Kirkpatrick DL, Periasamy M \& Walsh RA 1999 Effect of angiotensin-converting enzyme inhibition on protein kinase $\mathrm{C}$ and SR proteins in heart failure. American Journal of Physiology 276 H53-H62.

Thorburn J, Frost JA \& Thorburn A 1994a Mitogen-activated protein kinases mediate changes in gene expression, but not cytoskeletal organization associated with cardiac muscle cell hypertrophy. Journal of Cellular Biology 126 1565-1572.

Thorburn J, McMahon M \& Thorburn A $1994 b$ Raf-1 kinase activity is necessary and sufficient for gene expression changes but not sufficient for cellular morphology changes associated with cardiac myocyte hypertrophy. Journal of Biological Chemistry 269 30580-30586.

Toker A \& Cantley LC 1997 Signalling through the lipid products of phosphoinositide-3-OH kinase. Nature 387 673-676.

Wang D \& Sul HS 1998 Insulin stimulation of the fatty acid synthase promoter is mediated by the phosphatidylinositol 3-kinase pathway. Involvement of protein kinase B/Akt. Journal of Biological Chemistry 273 25420-25426.

Wang L, Wang X \& Proud CG 2000 Activation of mRNA translation in rat cardiac myocytes by insulin involves multiple rapamycinsensitive steps. American Journal of Physiology. Heart and Circulatory Physiology 278 H1056-H1068.

Wang Y, Huang S, Sah VP, Ross J Jr, Brown JH, Han J \& Chien KR 1998a Cardiac muscle cell hypertrophy and apoptosis induced by distinct members of the p38 mitogen-activated protein kinase family. Journal of Biological Chemistry 273 2161-2168. 
Wang Y, Su B, Sah VP, Brown JH, Han J \& Chien KR 19986 Cardiac hypertrophy induced by mitogen-activated protein kinase kinase 7 , a specific activator for c-Jun NH2-terminal kinase in ventricular muscle cells. Journal of Biological Chemistry 273 5423-5426.

Whelan RD \& Parker PJ 1998 Loss of protein kinase C function induces an apoptotic response. Oncogene 16 1939-1944.

Yamamoto Y, Yoshimasa Y, Koh M, Suga J, Masuzaki H, Ogawa Y, Hosoda K, Nishimura H, Watanabe Y, Inoue G \& Nakao K 2000 Constitutively active mitogen-activated protein kinase kinase increases GLUT1 expression and recruits both GLUT1 and
GLUT4 at the cell surface in 3T3-L1 adipocytes. Diabetes 49 332-339.

Zechner D, Thuerauf DJ, Hanford DS, McDonough PM \& Glembotski CC 1997 A role for the p38 mitogen-activated protein kinase pathway in myocardial cell growth, sarcomeric organization, and cardiac-specific gene expression. Journal of Cellular Biology 139 $115-127$.

Received in final form 20 November 2000 Accepted 8 December 2000 